\title{
Overexpression of GLP-1 receptors suppresses proliferation and cytokine release by airway smooth muscle cells of patients with chronic obstructive pulmonary disease via activation of ABCA1
}

\author{
YAN-HONG SUN ${ }^{1,2 *}$, LAN HE ${ }^{3 *}$, MING-YU YAN $^{4}$, RUI-QIAN ZHAO ${ }^{5}$, \\ $\mathrm{BIN} \mathrm{LI}^{6}$, FENG WANG ${ }^{2}$, YING YANG ${ }^{2}$ and HUA-PENG YU ${ }^{1}$ \\ ${ }^{1}$ Department of Respiratory Diseases, Zhujiang Hospital, Southern Medical University, Guangzhou, Guangdong 510282; \\ ${ }^{2}$ Department of Physiology, Inner Mongolia Medical University, Hohhot, Inner Mongolia Autonomous Region 010110; \\ ${ }^{3}$ Department of Respiratory Diseases, Affiliated Hospital of Inner Mongolia Medical University, Hohhot, \\ Inner Mongolia Autonomous Region 010050; ${ }^{4}$ Department of Respiratory and Critical Medicine, \\ The Third Affiliated Hospital of Inner Mongolia Medical University, Baotou, Inner Mongolia Autonomous Region 014010; \\ ${ }^{5}$ Graduate School, Inner Mongolia Medical University, Hohhot, \\ Inner Mongolia Autonomous Region 010110; ${ }^{6}$ Department of Histology and Embryology, Inner Mongolia \\ Medical University, Hohhot, Inner Mongolia Autonomous Region 010110, P.R. China
}

Received December 22, 2015; Accepted December 28, 2016

DOI: $10.3892 / \mathrm{mmr} .2017 .6618$

\begin{abstract}
Glucagon-like peptide-1 (GLP-1) is an important insulin secretagogue that possesses anti-inflammatory effects. GLP-1 receptor (GLP-1R) agonists have been demonstrated to serve a pivotal role in the treatment of obstructive lung diseases, including chronic obstructive pulmonary disease (COPD). However, the specific function and underlying mechanisms of GLP-1R in COPD remain uncertain. The aim of the present study was to investigate the action and underlying mechanisms of GLP-1R in airway smooth muscle (ASM) cells from COPD patients. GLP-1R expression levels were markedly decreased in ASM cells from COPD patients compared with those from healthy controls. ASM cell proliferation and migration, and the levels of the inflammatory cytokines
\end{abstract}

Correspondence to: Dr Hua-Peng Yu, Department of Respiratory Diseases, Zhujiang Hospital, Southern Medical University, 253 Gongye Da Dao Zhong, Guangzhou, Guangdong 510282, P.R. China

E-mail: yuhuapengtst@163.com

*Contributed equally

Abbreviations: GLP-1, glucagon-like peptide-1; COPD, chronic obstructive pulmonary disease; ASM, airway smooth muscle; ABCA1, adenosine triphosphate-binding cassette, subfamily A, member 1; LPS, lipopolysaccharide

Key words: chronic obstructive pulmonary disease, airway smooth muscle cell, glucagon-like peptide-1 receptor, adenosine triphosphate-binding cassette, subfamily A, member 1, proliferation, cytokine release interleukin (IL)-1 $\beta$, IL-4, tumor necrosis factor (TNF)- $\alpha$, and granulocyte-macrophage colony-stimulating factor (GM-CSF) were measured. Transfection of pcDNA3.1-GLP-1R had inhibitory effects on ASM cell proliferation and migration, whereas GLP-1R small interfering (si)RNA reversed these effects. Furthermore, the present study demonstrated that GLP-1R overexpression markedly suppressed IL-1 $\beta$, IL-4, TNF- $\alpha$ and GM-CSF levels. GLP-1R overexpression upregulated the expression levels of adenosine triphosphate-binding cassette, subfamily A, member 1 (ABCA1) in ASM cells, and the effects of GLP-1R on cell proliferation and migration, and inflammatory cytokine expression in ASM cells was abolished by siRNA-mediated silencing of ABCA1. The results of the present study suggested that GLP-1R contributes to COPD pathology, potentially via an ABCA1-mediated pathway.

\section{Introduction}

Chronic obstructive pulmonary disease (COPD), a chronic inflammatory disease involving the airways and lung parenchyma (1), is currently a primary cause of disability and death worldwide $(2,3)$. COPD is characterized by various clinical conditions, including emphysema and chronic bronchitis (4). It has been reported that airway inflammation serves a significant role in COPD, although the precise role remains unclear (5). The inflammatory process has been demonstrated to be involved in the complex pathogenesis of COPD (6), and the inflammatory response in COPD is associated with increased airway smooth muscle (ASM) cell hyperplasia, which results in increased ASM mass and small airway remodeling (7). As a result of airway wall remodeling in patients with COPD, ASM cells may produce inflammatory mediators (8). Thus, ASM cells may be a novel therapeutic target for the treatment of inflammation and airway remodeling in COPD patients. 
Mortality rates and lung function have previously been improved by glucagon-like peptide 1 (GLP-1) in a model of experimental obstructive lung disease in female mice (9). GLP-1, a potent glucoincretin hormone, is secreted by intestinal L-cells (10). GLP-1 increases insulin secretion and production via its receptor (GLP-1R) in pancreatic $\beta$-cells (11). GLP-1 additionally exerts various effects outside the pancreas, including regulation of food intake and appetite (12), inhibition of gastrointestinal motility and secretion (13) and a cardioprotective effect $(14,15)$. GLP-1 acts via GLP-1R on various types of target cells $(11,16)$; GLP-1R is expressed in the pancreatic islets, heart, brain, kidney, gastrointestinal tract and lungs $(15,17,18)$. GLP-1 serves a role in inflammation and may inhibit lipopolysaccharide (LPS)-induced cytokine secretion in various types of cells, including peritoneal macrophages and cortical astrocytes (19-21). However, although GLP-1R serves a role in obstructive lung disease, its exact underlying mechanisms remain unclear.

Hu et al (22) demonstrated that $\mathrm{G}$ protein-coupled receptor 119 (GPR119) significantly increased the expression levels of adenosine triphosphate-binding cassette, subfamily A, member 1 (ABCA1) via GLP-1R, and ABCA1 expression levels were markedly reduced by small interfering (si)RNA-mediated silencing of GLP-1R in a THP-1 macrophage cell line. ABCA1 is a member of a highly conserved transmembrane transport protein family, and is expressed in various mammalian tissues and cells $(23,24)$. ABCA1 serves a crucial role in pulmonary diseases and abnormalities (25), and ABCA1 overexpression in mouse vascular endothelial cells has been associated with ovalbumin-induced neutrophilic airway inflammation $(26,27)$. Therefore, the present study hypothesized that GLP-1R may serve an important role in COPD, and that ABCA1 is involved in the effects of GLP-1R. ASM cells were isolated from patients with COPD and a GLP-1R-overexpressing cell model was established to investigate the function and underlying mechanisms of GLP-1R. The present study provided evidence that GLP-1R is associated with ASM cell proliferation and the secretion of inflammatory cytokines.

\section{Materials and methods}

Subjects. The present study was approved by the Ethics Committee of the Zhujiang Hospital, Southern Medical University (Guangzhou, China). Written informed consent was obtained from each subject. Healthy controls $(\mathrm{n}=8)$ and patients with COPD $(n=12)$ were recruited (Table I) from the Department of Respiratory Diseases of Zhujiang Hospital.

ASM cell culture and transfection. ASM cells were isolated from bronchial biopsy specimens according to a method described previously (28). Isolated human ASM cells from eight healthy donors and twelve COPD donors were used at passage 3-4. Cells were maintained in Dulbecco's modified Eagle's medium (Invitrogen; Thermo Fisher Scientific, Inc., Waltham, MA, USA) supplemented with $20 \mu \mathrm{g} / \mathrm{ml}$ streptomycin, $4 \mathrm{mM} \mathrm{L}$-glutamine, $2.5 \mu \mathrm{g} / \mathrm{ml}$ amphotericin B, $20 \mathrm{U} / 1$ penicillin and $10 \%$ fetal bovine serum (FBS; Invitrogen; Thermo Fisher Scientific, Inc.). Human GLP-1R cDNA was purchased from OriGene Technologies, Inc. (Rockville, MD, USA) and GLP-1R cDNA was inserted into the HindIII/EcoRI site of pcDNA3.1 (Invitrogen; Thermo Fisher Scientific, Inc.) to form pcDNA3.1-GLP-1R. Cells were transfected with pcDNA3.1-GLP-1R or pcDNA3.1 vectors using Lipofectamine $2000^{\mathrm{TM}}$ (Invitrogen; Thermo Fisher Scientific, Inc.) according to the manufacturer's protocol.

MTT assay. ASM cell proliferation was determined by MTT assay as described previously (29). A total of $72 \mathrm{~h}$ following transfection, $5 \mathrm{mg} / \mathrm{ml}$ MTT was added to cells, which were subsequently incubated for $4 \mathrm{~h}$. Dimethyl sulfoxide (150 $\mu \mathrm{l})$ was added to dissolve the insoluble purple formazan. The colorimetric method is based on the reduction of the soluble tetrazolium dye MTT to its insoluble formazan. Absorbance was measured at a wavelength of $490 \mathrm{~nm}$ using a microplate reader.

Cell migration assay. ASM cell migration was measured using Transwell cell culture chambers $(8.0-\mu \mathrm{m}$ pore size; EMD Millipore, Billerica, MA, USA) as described previously (30). ASM cells were transfected with pcDNA301-GLP-1R or GLP-1R siRNA. Cells were trypsinized and seeded into the upper chamber of the Transwell insert $\left(1 \times 10^{5}\right.$ cells/well) and medium containing $10 \%$ FBS was added to the lower chamber. After $24 \mathrm{~h}$ of incubation, Giemsa dye was used to stain migrated cells for observation. Migrated cells were quantified under a light microscope (magnification, x200) (31).

Enzyme-linked immunosorbent assays (ELISA). The culture supernatants of ASM cells were collected and centrifugation was performed for $10 \mathrm{~min}$ at $1,500 \mathrm{x} \mathrm{g}$ and $4^{\circ} \mathrm{C}$ to remove particles and polymers. Interleukin (IL)- 6 and -8 , tumor necrosis factor (TNF)- $\alpha$, and granulocyte-macrophage colony-stimulating factor (GM-CSF) cytokine levels in ASM cell culture supernatants were measured using commercial ELISA kits (catalog nos. D6050, D8000C, DTA00C and DGM00, respectively; R\&D Systems, Inc., Minneapolis, MN, USA) according to the manufacturer's protocol.

Reverse transcription-quantitative polymerase chain reaction $(R T-q P C R)$. Total cellular RNA was extracted from ASM cells using TRIzol ${ }^{\circledR}$ reagent (Invitrogen; Thermo Fisher Scientific, Inc.). Total RNA (5 $\mu \mathrm{g}$ ) was used to reverse transcribe first-strand cDNA using a High-Capacity cDNA Archive kit (Applied Biosystems; Thermo Fisher Scientific, Inc.). GLP-1R and ABCA1 transcripts were quantified using SsoFast ${ }^{\mathrm{Tu}}$ EvaGreen ${ }^{\circledR}$ Supermix (Bio-Rad Laboratories, Inc., Hercules, CA, USA) according to the manufacturer's protocol and the amplification was performed using a ABI PRISM 7900HT sequence detection system (Applied Biosciences; Thermo Fisher Scientific, Inc.). The following PCR conditions were performed in this assay: $95^{\circ} \mathrm{C}$ for $10 \mathrm{~min}$; followed by 40 cycles of $95^{\circ} \mathrm{C}$ for $30 \mathrm{sec}, 55^{\circ} \mathrm{C}$ for $10 \mathrm{sec}$ and $72^{\circ} \mathrm{C}$ for $45 \mathrm{sec}$, followed by a final elongation step at $72^{\circ} \mathrm{C}$ for $5 \mathrm{~min}$. The following primers were used: GLP-1R, 5'-TCAAGGTCAACGGCTTAT TAGTGAA-3' (forward) and 5'-CCCAAGTGATGCAAGCAG AG-3' (reverse); ABCA1, 5'-AACAGTTTGTGGCCCTTT TG-3' (forward) and 5'-AGTTCCAGGCTGGGGTACTT-3' (reverse); $\beta$-actin, 5'-TCATGAAGTGTGACGTTGACATCC GT-3' (forward) and 5'-CTTAGAAGCATTTGCGGTGCA CGATG-3' (reverse). Results were calculated using the $2^{-\Delta \Delta \mathrm{Cq}}$ 
method, and are expressed as fold change compared with control values following normalization against $\beta$-actin (32).

Western blotting. Protein expression levels of GLP-1R and ABCA1 were measured by western blotting. Proteins were isolated from ASM cells using radioimmunoprecipitation assay lysis buffer (Invitrogen; Thermo Fisher Scientific, Inc.), subsequently, protein (40 $\mu \mathrm{g}$ per lane) was separated by $10 \%$ SDS-PAGE and subsequently transferred to a polyvinylidene difluoride membrane. Membranes were incubated with rabbit polyclonal anti-GLP-1R $(1: 1,000 ; 1 \mu \mathrm{g} / \mathrm{ml}$; catalog no. ab39072), mouse monoclonal anti-ABCA1 (1:500; catalog no. ab18180) or mouse monoclonal anti- $\beta$-actin $(1: 5,000$; $1 \mathrm{mg} / \mathrm{ml}$; catalog no. ab8226) antibodies (Abcam, Cambridge, MA, USA) overnight at $4^{\circ} \mathrm{C}$. Subsequently, the membrane was probed with horseradish peroxidase-conjugated goat anti-rabbit IgG (1:3,000; catalog no. ab6721; Abcam Cambridge, MA, USA) or rabbit anti-mouse $\operatorname{IgG}(1: 2,000$; catalog no. ab6728; Abcam.) for $1 \mathrm{~h}$ at room temperature. Protein bands were developed with an Enhanced Chemiluminescence detection kit (GE Healthcare Life Sciences, Chalfont, UK), and visualized and quantified using Image-Pro Plus 6.0 software (Media Cybernetics, Inc., Rockville, MD, USA).

RNA silencing. GLP-1R- and ABCA1-silenced cells were generated using Lipofectamine 2000 reagent according to the manufacturer's protocol. For cells transfected with pcDNA3.1-GLP-1R vector + ABCA1 or mock siRNA, co-transfection was performed. GLP-1R and control siRNAs were synthesized by Shanghai GenePharma Co., Ltd. (Shanghai, China). The sequences of the siRNA oligomers for GLP-1R were as follows: Forward, 5'-UCAUCAAGC UGUUUACAGATT-3' and reverse, 5'-UCUGUAAACAGC UUGAUGAAG-3'. The scrambled siRNA sequences of GLP-1R were as follows: Forward, 5'-UGUGGAUGACUG AGUACCUGA-3' and reverse, 5' -UCAGGUACUCAGUCA UCCACA-3'. ABCA1 siRNA was purchased from Santa Cruz Biotechnology, Inc. (Dallas, TX, USA; catalog no. sc-41136). The sequences of the siRNA oligomers for ABCA1 were as follows: Forward, 5'-GAACCUCACUUAGAAGAUU-3' and reverse, 5'-UUCUUGGAGUGAAAGUCUUCU-3'. The scrambled siRNA sequences used for ABCA1 were the same as scrambled GLP-1R siRNA sequences.

Statistical analysis. All statistical analyses were performed using SPSS software version 13.0 (SPSS, Chicago, IL, USA). Data are expressed as the mean \pm standard error. Differences between two groups were determined by the unpaired Student's t-test, and differences between multiple groups were determined by one-way analysis of variance followed by Fisher's least significant difference test. $\mathrm{P}<0.05$ was considered to indicate a statistically significant difference. All experiments were performed in quadruplicate and repeated three times.

\section{Results}

GLP-1R $m R N A$ and protein expression levels are reduced in ASM cells from COPD patients. The present study examined GLP-1R mRNA expression levels in ASM cells obtained from patients with COPD and healthy controls (Table I) by
Table I. Characteristics of subjects.

\begin{tabular}{lcc}
\hline Characteristic & $\begin{array}{c}\text { Healthy } \\
\text { subjects } \\
(\mathrm{n}=8)\end{array}$ & $\begin{array}{c}\text { COPD } \\
\text { patients } \\
(\mathrm{n}=12)\end{array}$ \\
\hline Age (years) & $44.6 \pm 4.15$ & $65.41 \pm 2.748^{\mathrm{a}}$ \\
Gender (male:female) & $5: 3$ & $4: 6$ \\
Duration of COPD (years) & $\mathrm{NA}$ & $16.35 \pm 2.28$ \\
FEV1 (\% predicted) & $103.9 \pm 4.08$ & $58.49 \pm 6.91^{\mathrm{a}}$ \\
FVC (\% predicted) & $109.7 \pm 6.1$ & $98.54 \pm 4.35$ \\
FEV1/ FVC ratio $(\%)$ & $86.39 \pm 3.24$ & $50.37 \pm 7.11^{\mathrm{a}}$ \\
\hline
\end{tabular}

Data are expressed as the mean \pm standard error. ${ }^{a} \mathrm{P}<0.05$ compared with healthy subjects. FVC, forced vital capacity; NA, not applicable; COPD, chronic obstructive pulmonary disorder; FEV1, forced expiratory volume at timed intervals of $1.0 \mathrm{sec}$; NA, not applicable.

RT-qPCR. GLP-1R mRNA expression levels were significantly decreased in ASM cells from patients with COPD, compared with healthy control cells ( $\mathrm{P}<0.05$; Fig. 1A). GLP-1R protein expression levels demonstrated the same effect, as revealed by western blot analysis $(\mathrm{P}<0.05$; Fig. 1B). To further investigate the effects of GLP-1R in ASM cells from COPD patients, overexpression or silencing of GLP-1R in ASM cells was performed. As revealed by RT-qPCR (Fig. 1C) and western blot analysis (Fig. 1D), the mRNA and protein expression levels of GLP-1R were significantly increased in ASM cells transfected with pcDNA3.1-Glp-1R for $72 \mathrm{~h}$, and significantly decreased in those transfected with GLP-1R siRNA for $48 \mathrm{~h}$. The mRNA and protein expression levels of GLP-1R were additionally measured in ASM cells transfected with pcDNA3.1-GLP-1R or GLP-1R siRNA for $24,48,72$ or $96 \mathrm{~h}$. The results indicated that the mRNA and protein expression levels of GLP-1R were significantly increased in ASM cells transfected with pcDNA3.1-Glp-1R, and significantly decreased in those transfected with GLP-1R siRNA (data not shown).

Effect of GLP-1R overexpression on ASM cell proliferation and migration. ASM cells from COPD patients demonstrated reduced proliferation following GLP-1R overexpression compared with the pcDNA3.1 empty-plasmid group Additionally, ASM cells transfected with GLP-1R siRNA exhibited increased proliferation by $32 \%$ compared with the siMock group (Fig. 2A). ASM cell migration was subsequently determined, and the results were similar to the proliferation study. GLP-1R overexpression suppressed the migration of ASM cells, whereas silencing increased ASM cell migration (Fig. 2B). These data indicated that GLP-1R overexpression reduces cell proliferation and migration, and therefore may serve a role in airway remodeling in COPD patients.

Effect of GLP-1R overexpression on IL-6, IL-8, TNF- $\alpha$ and GM-CSF release. To determine whether GLP-1R overexpression mediates ASM cell inflammatory cytokine release, the levels of IL-6, IL-8, TNF- $\alpha$ and GM-CSF were measured. Cultured ASM cells isolated from patients with COPD 
A

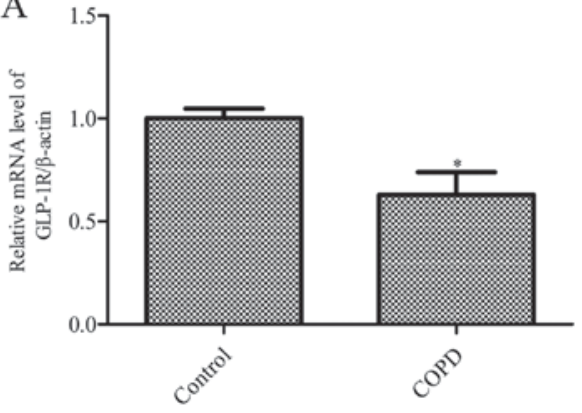

$\mathrm{C}$

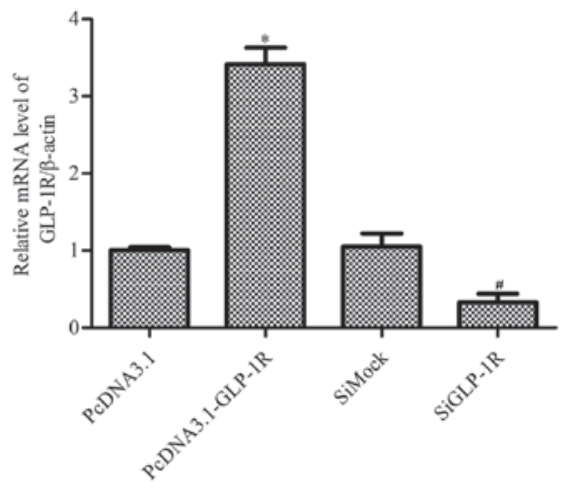

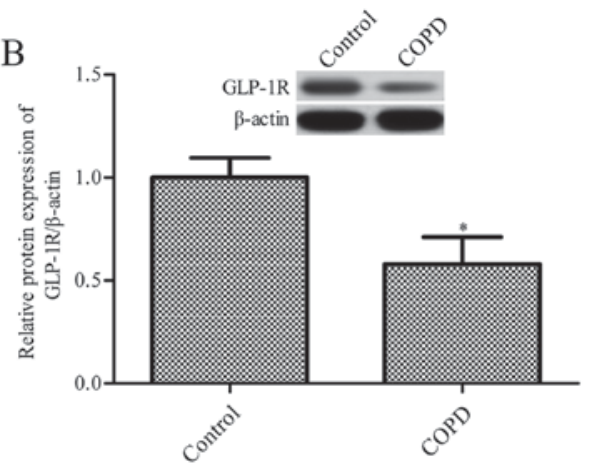

$\mathrm{D}$

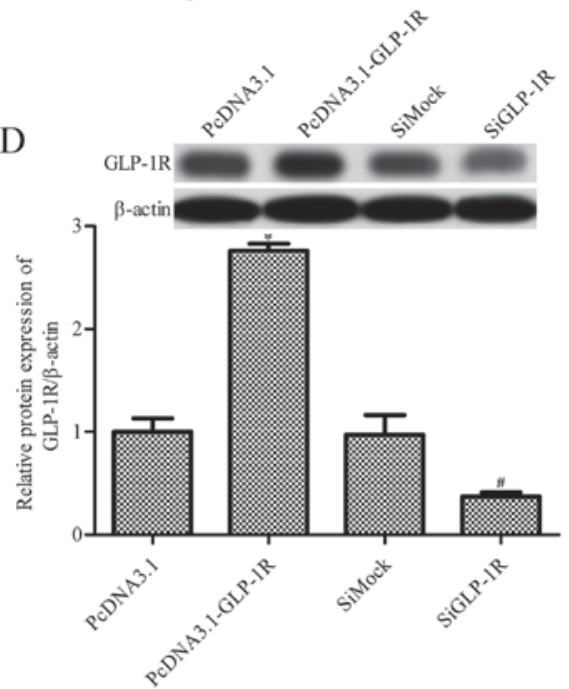

Figure 1. GLP-1R expression is reduced in ASM cells from COPD patients. GLP-1R (A) mRNA and (B) protein expression levels in ASM cells were measured by RT-qPCR and western blot analysis, respectively, in ASM cells isolated from COPD patients and healthy controls. "P<0.05 vs. control. ASM cells from COPD patients were transfected with pcDNA3.1-GLP-1R or GLP-1R siRNA. GLP-1R-overexpressed or -silenced ASM cells from COPD patients were assessed by (C) RT-qPCR and (D) western blot analysis to measure GLP-1R mRNA and protein expression levels, respectively. $\beta$-actin served as an internal control. Data are presented as the mean \pm standard error. ${ }^{*} \mathrm{P}<0.05$ vs. pcDNA3.1 group and ${ }^{\#} \mathrm{P}<0.05$ vs. siMock group. RT-qPCR, reverse transcription-quantitative polymerase chain reaction; ASM, airway smooth muscle; GLP-1R, glucagon-like peptide 1 receptor; COPD, chronic obstructive pulmonary disorder; si, small interfering.
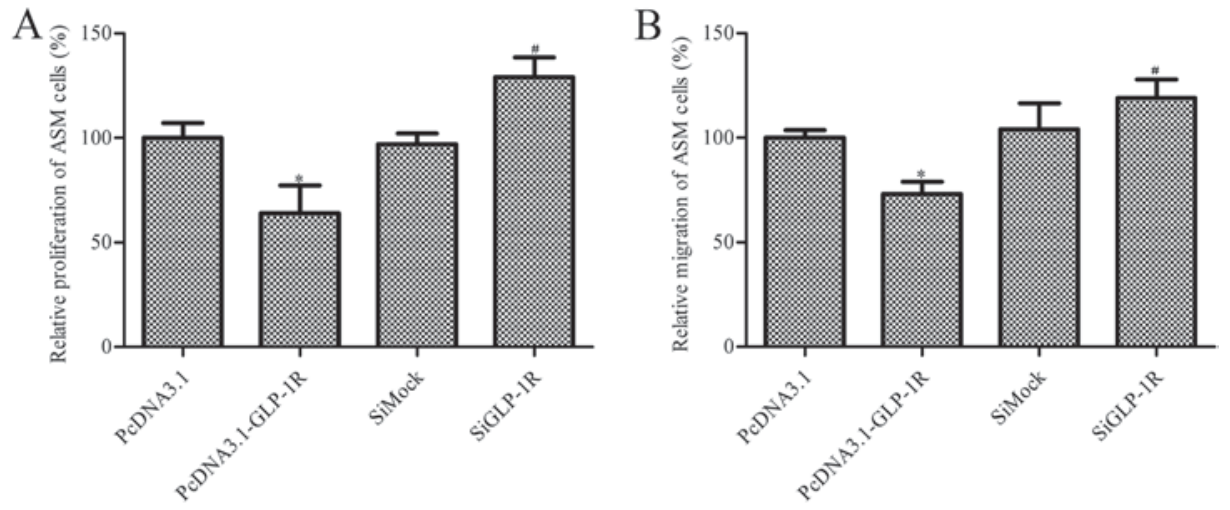

Figure 2. Effects of GLP-1R on proliferation and migration of ASM cells from COPD patients. Cells from COPD patients were transfected with pcDNA3.1-GLP-1R or GLP-1R siRNA. Cell (A) proliferation and (B) migration were assessed by MTT and Transwell assays, respectively. GLP-1R overexpression inhibited ASM cell proliferation and migration. Data are presented as the mean \pm standard error. ${ }^{*} \mathrm{P}<0.05$ vs. pcDNA3.1 group and ${ }^{\#} \mathrm{P}<0.05$ vs. siMock group. GLP-1R, glucagon-like peptide 1 receptor; ASM, airway smooth muscle; COPD, chronic obstructive pulmonary disorder; si, small interfering.

released increased levels of IL-6, IL-8, TNF- $\alpha$ and GM-CSF compared with ASM cells from healthy control subjects $(\mathrm{P}<0.05$; Fig. 3A). In addition, GLP-1R overexpression inhibited the release of IL-6, IL-8, TNF- $\alpha$ and GM-CSF, whereas its ablation increased the release of these inflammatory cytokines (Fig. 3B-E).
GLP-1R overexpression markedly upregulates ABCAI expression levels. GLP-1R may upregulate the expression levels of ABCA1, and previous studies have indicated that ABCA1 serves an important role in airway inflammation $(23,27)$. Thus, the present study aimed to determine the effects of GLP-1R on ABCA1 expression levels. RT-qPCR 


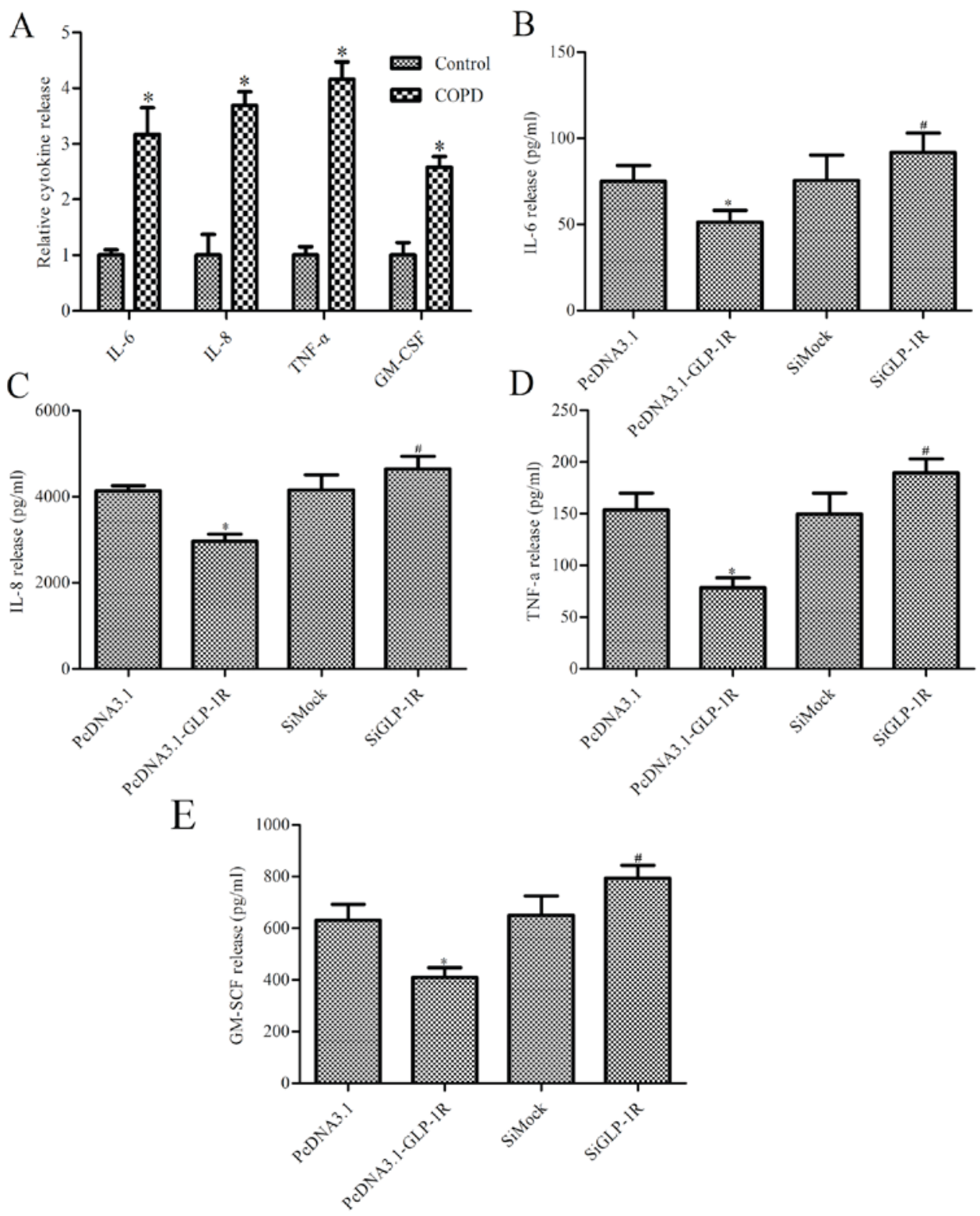

Figure 3. Anti-inflammatory effects of GLP-1R on ASM cells from COPD patients. Cells from COPD patients were transfected with pcDNA3.1-GLP-1R or GLP-1R siRNA. (A) Relative cytokine release in ASM cells from healthy controls and patients with COPD. * $\mathrm{P}<0.05$ vs. control. ELISA was used to detect the expression levels of (B) IL-6, (C) IL-8, (D) TNF- $\alpha$ and (E) GM-CSF. "P<0.05 vs. pcDNA3.1 group and " $\mathrm{P}<0.05$ vs. siMock group. Data are presented as the mean \pm standard error. si, small interfering; IL, interleukin; TNF- $\alpha$, tumor necrosis factor- $\alpha$; GM-CSF, granulocyte-macrophage colony-stimulating factor; GLP-1R, glucagon-like peptide 1 receptor; ASM, airway smooth muscle; COPD, chronic obstructive pulmonary disorder.

and western blotting were performed to assess the expression levels of ABCA1 in ASM cells obtained from patients with COPD and healthy control subjects. mRNA (Fig. 4A) and protein (Fig. 4B) expression levels of ABCA1 were reduced in ASM cells from COPD patients compared with the healthy control subjects $(\mathrm{P}<0.05)$. Furthermore, GLP-1R overexpression increased the expression levels of ABCA1 in ASM cells obtained from patients with COPD, whereas GLP-1R siRNA decreased ABCA1 expression levels $(\mathrm{P}<0.05$; Fig. 4C and D).

GLP-1R-mediated cell proliferation, migration and cytokine release is dependent on ABCAl expression. The above results suggested that GLP-1R increases the expression levels of ABCA1, and it was therefore hypothesized that the effects of GLP-1R on ASM cell proliferation, migration and cytokine release are dependent on altered ABCA1 expression levels. To further investigate the interaction between ABCA1 and GLP-1R in ASM cells obtained from patients with COPD, ABCA1-silenced ASM cells were established. As presented in Fig. 5A, ABCA1 siRNA markedly inhibited the mRNA expression levels of ABCA1. Treatment with pcDNA3.1-GLP-1R significantly inhibited proliferation (Fig. 5B) and migration (Fig. 5C) of ASM cells from COPD patients, whereas this effect was ameliorated by co-transfection with ABCA1 siRNA $(\mathrm{P}<0.05)$. IL-6, IL-8, TNF- $\alpha$ and GM-CSF levels were additionally measured, and the results indicated that ABCA1 siRNA reversed the GLP-1R overexpression-induced decrease in IL-6, IL-8, TNF- $\alpha$ and GM-CSF expression levels ( $\mathrm{P}<0.05$; Fig. 5D). 

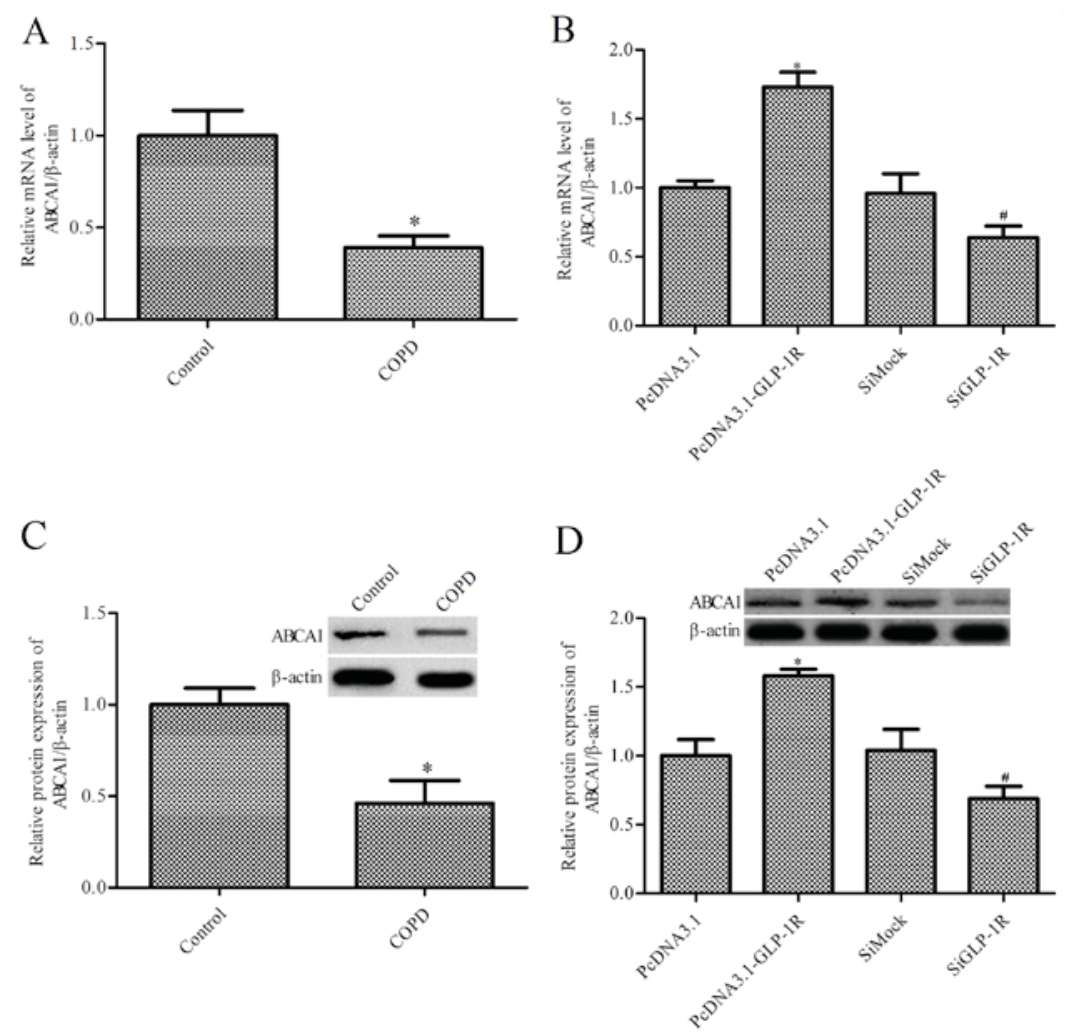

Figure 4. GLP-1R-mediated ABCA1 expression in ASM cells from COPD patients. Cells from COPD patients were transfected with pcDNA3.1-GLP-1R or GLP-1R siRNA. ABCA1 mRNA expression in (A) COPD and healthy control ASM cells and (B) transfected ASM cells, and ABCA1 protein expression levels in (C) COPD and healthy control ASM cells and (D) transfected ASM cells were determined by reverse transcription-quantitative polymerase chain reaction and western blotting, respectively. $\beta$-actin served as an internal control. Data are presented as the mean \pm standard error. " $\mathrm{P}<0.05$ vs. control group in A and $\mathrm{C}$; ${ }^{*} \mathrm{P}<0.05$ vs. pcDNA3.1 group and ${ }^{~} \mathrm{P}<0.05$ vs. siMock group in B and $\mathrm{D}$. si, small interfering; GLP-1R, glucagon-like peptide 1 receptor; ASM, airway smooth muscle; COPD, chronic obstructive pulmonary disorder; ABCA1, adenosine triphosphate-binding cassette, subfamily A, member 1.
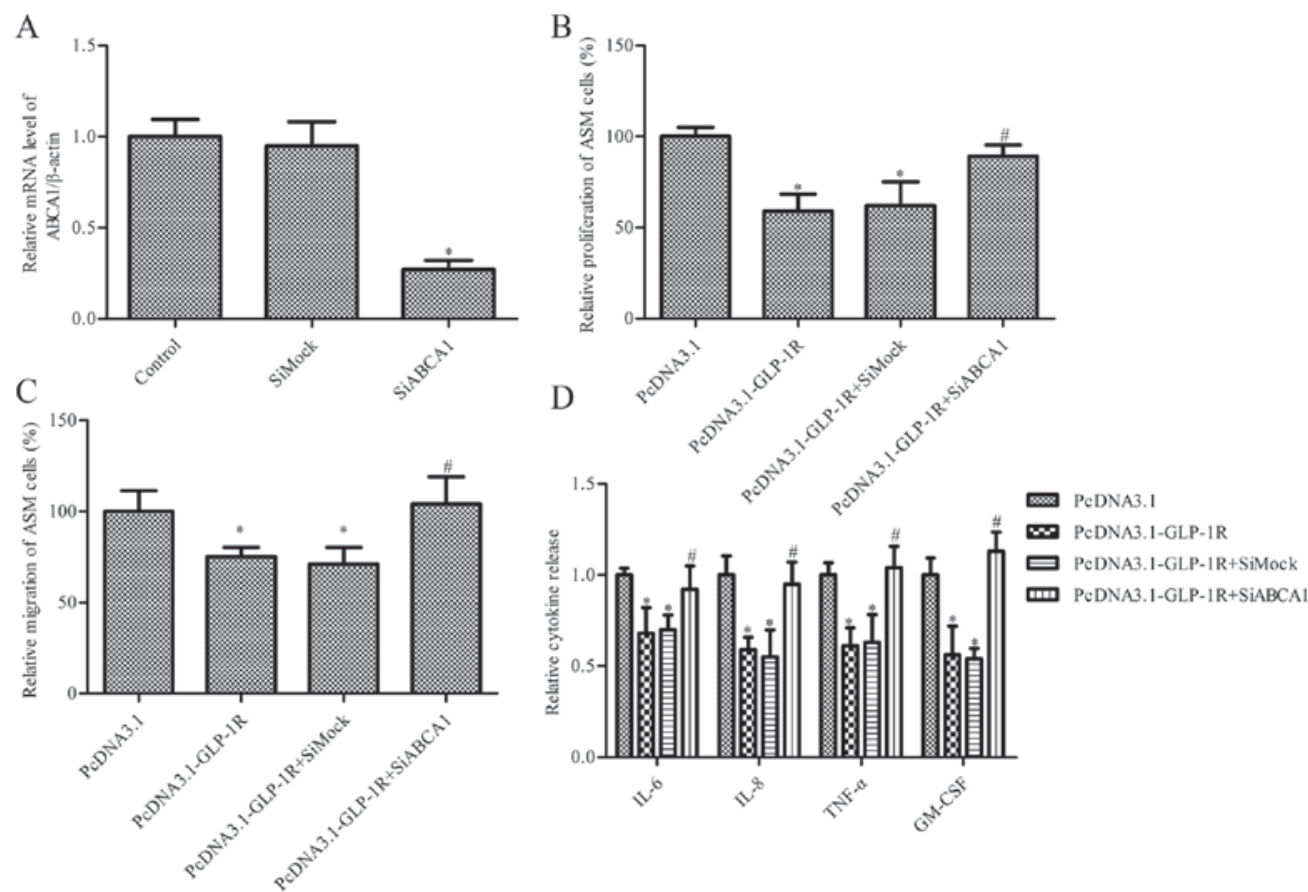

Figure 5. Effect of ABCA1 silencing on GLP-1R-mediated ASM cell proliferation, migration and cytokine release. Cells from COPD patients were transfected with pcDNA3.1-GLP-1R and ABCA1 siRNA. (A) mRNA expression levels of ABCA1; $\beta$-actin served as an internal control. "P<0.05 vs. control. (B) An MTT assay was used to measure ASM cell proliferation. (C) Cell migration was measured using a Transwell assay. (D) The levels of IL-6, IL-8, TNF- $\alpha$ and GM-CSF secreted by ASM cells obtained from COPD patients were detected by ELISA. Data are presented as the mean \pm standard error. ${ }^{*} \mathrm{P}<0.05$ vs. pcDNA3.1 group and ${ }^{\#} \mathrm{P}<0.05$ vs. pcDNA3.1-Glp-1R group + siMock. si, small interfering; GLP-1R, glucagon-like peptide 1 receptor; ASM, airway smooth muscle; COPD, chronic obstructive pulmonary disorder; ABCA1, adenosine triphosphate-binding cassette, subfamily A, member 1; IL, interleukin; TNF- $\alpha$, tumor necrosis factor- $\alpha$; GM-CSF, granulocyte-macrophage colony-stimulating factor. 


\section{Discussion}

The present study demonstrated decreased expression levels of GLP-1R and ABCA1 in ASM cells from patients with COPD. Furthermore, overexpression of GLP-1R suppressed proliferation and cytokine release by ASM cells from patients with COPD via increased ABCA1 expression levels.

GLP-1 serves a cardioprotective role in humans following myocardial infarction (MI) and in animal models of MI (14). Liu et al (33) demonstrated that chronic treatment with GLP-1 or AC3174 improves glucose metabolism, fluid balance and respiratory efficiency in a rat model of congestive heart failure, compared with vehicle control animals. GLP-1Rs are known to serve an important role in models of experimental obstructive lung disease in female mice (9); GLP-1R agonists were demonstrated to reduce mortality rates and improve lung function, and may have therapeutic potential for the treatment of obstructive pulmonary diseases (9). However, the specific function and underlying mechanisms of action remain unclear. Consistent with this study, the present study revealed that GLP-1R serves a crucial role in COPD in vitro. GLP-1R overexpression significantly suppressed proliferation and cytokine release by ASM cells from patients with COPD, which may serve roles in airway remodeling and inflammation.

Notably, COPD is analogous to asthma in that the two diseases are associated with chronic inflammation and smooth muscle hyperplasia. ASM cells may mediate immune modulation and inflammation in the airway via secretion of inflammatory mediators and cytokines (34). Furthermore, ASM cell hyperplasia contributes to an increase in ASM mass and results in small airway remodeling in COPD (7). Adenosine triphosphate-binding cassette transporters, including ABCA1, are known to be important in the pathogenesis of ASM cells. ABCA1 may serve a critical role in airway diseases, including asthma, via dysregulation of cholesterol homeostasis (35). Although the function of ABCA1 has been well characterized in ASM cells, its role in COPD remains unclear.

The $A B C A 1$ gene has previously been demonstrated to be a target of liver X receptors (LXRs) $(7,26,33)$; macrophage expression of ABCA1 and intestinal cholesterol absorption was abolished in LXR-null mice. Mostafa et al (36) revealed that GLP-1 may modulate ABCA1 expression levels in adipocytes via an LXR- $\alpha$-mediated process. Hu et al (22) demonstrated that GLP-1R-silencing markedly inhibits ABCA1 expression in THP-1 macrophages. Consistent with these studies, the present study revealed that GLP-1R overexpression promoted ABCA1 expression levels, whereas GLP-1R silencing inhibited its expression levels. Using siRNA knockdown approaches, ABCA1 was demonstrated to be necessary for GLP-1R-induced cell proliferation, migration and cytokine release inhibition in ASM cells.

In conclusion, the present study revealed that overexpression of GLP-1R significantly reduces proliferation, migration and cytokine release in ASM cells from COPD patients; this involved a significant increase in ABCA1 expression levels. This provided evidence to suggest that GLP-1R may be a potential therapeutic target for the treatment of COPD.

\section{References}

1. Tangedal S, Aanerud M, Persson LJ, Brokstad KA, Bakke PS and Eagan TM: Comparison of inflammatory markers in induced and spontaneous sputum in a cohort of COPD patients. Respir Res 15: 138, 2014.

2. Niewoehner DE: Clinical practice. Outpatient management of severe COPD. N Engl J Med 362: 1407-1416, 2010.

3. Vogelmeier C, Hederer B, Glaab T, Schmidt H, Rutten-van Mölken MP, Beeh KM, Rabe KF and Fabbri LM; POET-COPD Investigators: Tiotropium versus salmeterol for the prevention of exacerbations of COPD. N Engl J Med 364: 1093-1103, 2011.

4. Kang MJ, Yoon CM, Kim BH, Lee CM, Zhou Y, Sauler M, Homer R, Dhamija A, Boffa D, West AP, et al: Suppression of NLRX1 in chronic obstructive pulmonary disease. J Clin Invest 125: 2458-2462, 2015.

5. Brusasco V, Crimi E and Pellegrino R: Airway inflammation in COPD: Friend or foe? Am J Respir Crit Care Med 176: 425-426, 2007.

6. Ogawa E, Elliott WM, Hughes F, Eichholtz TJ, Hogg JC and Hayashi S: Latent adenoviral infection induces production of growth factors relevant to airway remodeling in COPD. Am J Physiol Lung Cell Mol Physiol 286: L189-L197, 2004.

7. Michaeloudes C, Wiegman C, Kirkham P, Chung KF and Adcock I: Mitochondrial reactive oxygen species (ROS) mediate proliferation and cytokine release in airway smooth muscle cells of patients with COPD. European Respir J 44: P3845, 2014.

8. Chung KF: The role of airway smooth muscle in the pathogenesis of airway wall remodeling in chronic obstructive pulmonary disease. Proc Am Thorac Soc 2: 347-354; 371-372, 2005.

9. Viby NE, Isidor MS, Buggeskov KB, Poulsen SS, Hansen JB and Kissow H: Glucagon-like peptide-1 (GLP-1) reduces mortality and improves lung function in a model of experimental obstructive lung disease in female mice. Endocrinology 154: 4503-4511, 2013.

10. Drucker DJ: Glucagon-like peptides. Diabetes 47: 159-169, 1998.

11. Hou Y, Ernst SA, Heidenreich K and Williams JA: Glucagon-like peptide-1 receptor is present in pancreatic acinar cells and regulates amylase secretion through cyclic AMP. Am J Physiol Gastrointest Liver Physiol 310: G26-G33: 2016

12. Tang-Christensen M, Vrang N and Larsen PJ: Glucagon-like peptide 1(7-36) amide's central inhibition of feeding and peripheral inhibition of drinking are abolished by neonatal monosodium glutamate treatment. Diabetes 47: 530-537, 1998.

13. Nauck MA, Niedereichholz U, Ettler R, Holst JJ, Orskov C, Ritzel R and Schmiegel WH: Glucagon-like peptide 1 inhibition of gastric emptying outweighs its insulinotropic effects in healthy humans. Am J Physiol 273: E981-E988, 1997.

14. Noyan-Ashraf MH, Momen MA, Ban K, Sadi AM, Zhou YQ, Riazi AM, Baggio LL, Henkelman RM, Husain $M$ and Drucker DJ: GLP-1R agonist liraglutide activates cytoprotective pathways and improves outcomes after experimental myocardial infarction in mice. Diabetes 58: 975-983, 2009.

15. Ban K, Noyan-Ashraf MH, Hoefer J, Bolz SS, Drucker DJ and Husain M: Cardioprotective and vasodilatory actions of glucagon-like peptide 1 receptor are mediated through both glucagon-like peptide 1 receptor-dependent and -independent pathways. Circulation 117: 2340-2350, 2008.

16. Dillon JS, Tanizawa Y, Wheeler MB, Leng XH, Ligon BB, Rabin DU, Yoo-Warren H, Permutt MA and Boyd AE III: Cloning and functional expression of the human glucagon-like peptide-1 (GLP-1) receptor. Endocrinology 133: 1907-1910, 1993.

17. Bullock BP, Heller RS and Habener JF: Tissue distribution of messenger ribonucleic acid encoding the rat glucagon-like peptide-1 receptor. Endocrinology 137: 2968-2978, 1996.

18. Campos RV, Lee YC and Drucker DJ: Divergent tissue-specific and developmental expression of receptors for glucagon and glucagon-like peptide-1 in the mouse. Endocrinology 134: 2156-2164, 1994.

19. Arakawa M, Mita T, Azuma K, Ebato C, Goto H, Nomiyama T, Fujitani Y, Hirose T, Kawamori R and Watada H: Inhibition of monocyte adhesion to endothelial cells and attenuation of atherosclerotic lesion by a glucagon-like peptide-1 receptor agonist, exendin-4. Diabetes 59: 1030-1037, 2010.

20. Iwai T, Ito S, Tanimitsu K, Udagawa S and Oka J: Glucagon-like peptide-1 inhibits LPS-induced IL-1beta production in cultured rat astrocytes. Neurosci Res 55: 352-360, 2006.

21. $\mathrm{Ku} \mathrm{HC}$ and Chen WP and Su MJ: GLP-1 signaling preserves cardiac function in endotoxemic Fischer 344 and DPP4-deficient rats. Naunyn-Schmiedeberg's Arch Pharmacol 382: 463-474, 2010. 
22. Hu YW, Yang JY, Ma X, Chen ZP, Hu YR, Zhao JY, Li SF, Qiu YR, Lu JB, Wang YC, et al: A lincRNADYNLRB2-2/GPR119/GLP-1R/ABCA1-dependent signal transduction pathway is essential for the regulation of cholesterol homeostasis. J Lipid Res 55: 681-697, 2014.

23. Langmann T, Klucken J, Reil M, Liebisch G, Luciani MF, Chimini G, Kaminski WE and Schmitz G: Molecular cloning of the human ATP-binding cassette transporter 1 (hABC1): Evidence for sterol-dependent regulation in macrophages. Biochem Biophys Res Commun 257: 29-33, 1999.

24. Bortnick AE, Rothblat GH, Stoudt G, Hoppe KL, Royer LJ, McNeish $\mathrm{J}$ and Francone OL: The correlation of ATP-binding cassette $1 \mathrm{mRNA}$ levels with cholesterol efflux from various cell lines. J Biol Chem 275: 28634-28640, 2000.

25. Bates SR, Tao JQ, Collins HL, Francone OL and Rothblat GH: Pulmonary abnormalities due to ABCA1 deficiency in mice. Am J Physiol Lung Cell Mol Physiol 289: L980-L989, 2005.

26. Dai C, Boris V, Yao X, Meyer K, Karen K, Nugent GJ, Qu X, $\mathrm{Yu} \mathrm{ZX}$, Remaley A and Levine SJ: Expression Of Human Abcal In Mouse Vascular Endothelial Cells Attenuates Ovalbumin-Induced Neutrophilic Airway Inflammation. Am J Respir Crit Care Med 185: A5637, 2012.

27. Dai C, Yao X, Vaisman B, Brenner T, Meyer KS, Gao M, Keeran KJ, Nugent GZ, Qu X, Yu ZX, et al: ATP-binding cassette transporter 1 attenuates ovalbumin-induced neutrophilic airway inflammation. Am J Respir Cell Mol Biol 51: 626-636, 2014.

28. Michaeloudes C, Sukkar MB, Khorasani NM, Bhavsar PK and Chung KF: TGF- $\beta$ regulates Nox 4, MnSOD, and catalase expression ,and IL-6 release in airway smooth muscle cells. Am J Physiol Lung Cell Mol Physiol 300: L295-L304, 2011.

29. Sturrock A, Huecksteadt TP, Norman K, Sanders K, Murphy TM, Chitano P, Wilson K, Hoidal JR and Kennedy TP: Nox4 mediates TGF-beta1-induced retinoblastoma protein phosphorylation, proliferation, and hypertrophy in human airway smooth muscle cells Am J Physiol Lung Cell Mol Physiol 292: L1543-L1555, 2007.
30. Lin SS, Lai KC, Hsu SC, Yang JS, Kuo CL, Lin JP, Ma YS, Wu CC and Chung JG: Curcumin inhibits the migration and invasion of human A549 lung cancer cells through the inhibition of matrix metalloproteinase-2 and-9 and Vascular Endothelial Growth Factor (VEGF). Cancer Lett 285: 127-133, 2009.

31. Hsu SC, Kuo CL, Lin JP, Lee JH, Lin CC, Su CC, Yang MD and Chung JG: Crude extracts of Euchresta formosana radix inhibit invasion and migration of human hepatocellular carcinoma cells. Anticancer Res 27: 2377-2384, 2007.

32. Livak KJ and Schmittgen TD: Analysis of relative gene expression data using real-time quantitative PCR and the 2(-Delta Delta $\mathrm{C}(\mathrm{T})$ ) method. methods 25: 402-408, 2001.

33. Liu Q, Anderson C, Broyde A, Polizzi C, Fernandez R, Baron A and Parkes DG: Glucagon-like peptide-1 and the exenatide analogue AC3174 improve cardiac function, cardiac remodeling, and survival in rats with chronic heart failure. Cardiovase Diabetol 9: 76, 2010.

34. Lazaar AL and Panettieri RA Jr: Airway smooth muscle as an immunomodulatory cell: A new target for pharmacotherapy? Curr Opin Pharmacol 1: 259-264, 2001.

35. Delvecchio CJ, Bilan P, Nair P and Capone JP: LXR-induced reverse cholesterol transport in human airway smooth muscle is mediated exclusively by ABCA1. Am J Physiol Lung Cell Mol Physiol 295: L949-L957, 2008.

36. Mostafa AM, Hamdy NM, El-Mesallamy $\mathrm{HO}$ and Abdel-Rahman SZ: Glucagon-like peptide 1 (GLP-1)-based therapy upregulate LXR-ABCA1/ABCG1 cascade in adipocytes. Biochem Biophys Res Commun 468: 900-905, 2015. 